Wright State University

CORE Scholar

Physics Faculty Publications

Physics

$8-2000$

\title{
Properties of Semi-Insulating GaAs:Fe Grown by Hydride Vapor Phase Epitaxy
}

E. Rodríguez Messmer

D. Söderström

P. Hult

S. Marcinkevicius

S. Lourdudoss

See next page for additional authors

Follow this and additional works at: https://corescholar.libraries.wright.edu/physics

Part of the Physics Commons

\section{Repository Citation}

Rodríguez Messmer, E., Söderström, D., Hult, P., Marcinkevicius, S., Lourdudoss, S., \& Look, D. C. (2000).

Properties of Semi-Insulating GaAs:Fe Grown by Hydride Vapor Phase Epitaxy. Journal of The

Electrochemical Society, 147 (8), 3109-3110.

https://corescholar.libraries.wright.edu/physics/703

This Article is brought to you for free and open access by the Physics at CORE Scholar. It has been accepted for inclusion in Physics Faculty Publications by an authorized administrator of CORE Scholar. For more information, please contact library-corescholar@wright.edu. 


\section{Authors}

E. Rodríguez Messmer, D. Söderström, P. Hult, S. Marcinkevicius, S. Lourdudoss, and David C. Look 


\section{Properties of Semi-insulating GaAs:Fe Grown by Hydride Vapor Phase Epitaxy}

E. Rodríguez Messmer, D. Söderström, P. Hult, S. Marcinkevicius, S. Lourdudoss and D.

C. Look

J. Electrochem. Soc. 2000, Volume 147, Issue 8, Pages 3109-3110.

doi: $10.1149 / 1.1393865$

Email alerting

Receive free email alerts when new articles cite this article - sign up in the service box at the top right corner of the article or click here

To subscribe to Journal of The Electrochemical Society go to: http://jes.ecsdl.org/subscriptions

(C) 2000 ECS - The Electrochemical Society 


\title{
Properties of Semi-insulating GaAs:Fe Grown by Hydride Vapor Phase Epitaxy
}

\author{
E. Rodríguez Messmer, ${ }^{\text {a,z }}$ D. Söderström, ${ }^{a}$ P. Hult, ${ }^{a}$ S. Marcinkevicius, ${ }^{a}$ S. Lourdudoss, ${ }^{\text {a,* }}$ D. C. Look \\ ${ }^{a}$ Department of Electronics, Royal Institute of Technology, SE-164 40 Kista, Sweden \\ ${ }^{b}$ Semiconductor Research Center, Wright State University, Dayton, Ohio 45435, USA
}

\begin{abstract}
In this paper we analyze GaAs grown by hydride vapor phase epitaxy (HVPE) and doped with four different iron concentrations between $4 \times 10^{16}$ and $4.5 \times 10^{20} \mathrm{~cm}^{-3}$. From temperature dependent current-voltage measurements we observed the highest resistivity in the lowest doped sample. We also quantified the activation energy. These results together with those of time resolved photoluminescence measurements indicate that in the sample with the lowest Fe concentration, EL2 may be dominant. From the analysis of the time resolved photoluminescence measurements, the intrinsic EL2 concentration and the electron and hole capture cross sections of $\mathrm{Fe}$ in GaAs were estimated.

(c) 2000 The Electrochemical Society. S0013-4651(00)02-041-3. All rights reserved.
\end{abstract}

Manuscript received Febraury 9, 2000. This was, in part, paper 1156 presented at the Honolulu, Hawaii, Meeting of the Society, October 17-22, 1999.

Semi-insulating (SI) GaAs is an important material for GaAsbased electronic and optoelectronic devices. Because of its high thermal conductance it can be useful for components, e.g. short wavelength vertical cavity surface emitting lasers (VCSEL), where heat dissipation is a major issue. Normally, when used as a confinement layer in a buried heterostructure, SI-GaAs has poor electrical confinement due to lower bandgap than the active region, and poor optical mode confinement due to its higher refractive index. But it has been shown that as a regrown layer in a buried heterostructure VCSEL, $\mathrm{GaAs}$ acts as an antiguiding layer which offers the possibility of producing high power single mode VCSELs. ${ }^{1}$ These advantages apply also to new emerging materials, e.g., GaInAsN-based on GaAs structures. Since regrowth of these devices is simpler in hydride vapor phase epitaxy (HVPE), we analyze in this work iron doped SIGaAs:Fe. This material has been grown with different iron concentrations by HVPE and has been characterized electrically with temperature dependent current voltage (I-V-T) measurements, and optically with time resolved photoluminescence (TR-PL) measurements.

\section{Experimental}

Iron doped GaAs was grown in a homemade HVPE reactor ${ }^{2}$ on an $\mathrm{n}-\mathrm{GaAs}$ substrate at $735^{\circ} \mathrm{C}$. The V/III ratio was 3.6 and the growth time was $30 \mathrm{~min}$, which corresponds to an approximate layer thickness of $2 \mu \mathrm{m}$. Four different concentrations of iron $\left(4 \times 10^{16}, 5 \times\right.$ $10^{17}, 1 \times 10^{20}$, and $4.5 \times 10^{20} \mathrm{~cm}^{-3}$ ) were achieved by varying the temperature of the iron source. On top of the GaAs:Fe layer, sulfur doped GaAs ( $n=8.7 \times 10^{18} \mathrm{~cm}^{-3}, 0.4 \mu \mathrm{m}$ layer thickness) was grown to obtain an ohmic contact for resistivity measurements. After conventional lithography and depositing AuGe for the electrical contact, cylindrical mesas of $280 \mu \mathrm{m}$ diam were wet etched through the n-layer using the contact metal as mask. The etchant was $31 \%$ $\mathrm{H}_{2} \mathrm{O}_{2}: 85 \% \mathrm{H}_{3} \mathrm{PO}_{4}: \mathrm{H}_{2} \mathrm{O}$ (volume ratio 1:5:200). Additionally, one reference sample with unintentionally doped GaAs (and without the $\mathrm{n}$-GaAs layer) was grown on a SI-GaAs substrate. Secondary-ion mass spectrometry measurements gave the total iron concentration in the samples. I-V-T measurements were performed by varying the voltage between $1 \mathrm{mV}$ and $20 \mathrm{~V}$ at temperatures between 25 and $225^{\circ} \mathrm{C}$. The values of the resistivity were deduced from these measurements. The PL transients were measured at room temperature by an up-conversion technique which yields a resolution of $\sim 150 \mathrm{fs}$.

\section{Results and Discussion}

$I$ - V-T measurements. - From I-V-T measurements it is possible to extract information about the resistivity and activation energy. The resistivity at $0.1 \mathrm{~V}$ and $25^{\circ} \mathrm{C}$ is given in Fig. 1 and shows that, sur-

\footnotetext{
* Electrochemical Society Active Member.

z E-mail: messmer@ele.kth.se
}

prisingly, the highest resistivity is obtained for the lowest iron concentration (sample B). Considering the other three samples (samples $\mathrm{D}, \mathrm{E}$, and F), a maximum resistivity is obtained for sample $\mathrm{E}$ and yet less than that of B. The current density $J$ at low electric fields $\mathbf{F}$ is given by

$$
J=C \mathbf{F} \exp (-\mathrm{e} \phi / k T)
$$

where $\mathrm{C}$ is a constant, $\phi$ the thermal activation energy, $k$ the Boltzmann constant, and $T$ the temperature. When plotting $\ln J v s .1 / T$, the slope of the plot yields the activation energy divided by the Boltzmann constant. These Arrhenius plots at $0.1 \mathrm{~V}$ are given in Fig. 2. The obtained activation energy was $0.72 \mathrm{eV}$ for sample B and around $0.5 \mathrm{eV}$ for samples $\mathrm{D}, \mathrm{E}$, and F. A literature survey indicates that $0.72 \mathrm{eV}$ level is associated with the EL2 defect (a deep donor) and the $0.5 \mathrm{eV}$ level with $\mathrm{Fe}$ (a deep acceptor). ${ }^{3}$ This suggests that the highest resistivity in sample B is due to EL2. The revelation of EL2 in sample B can be due to one of the following two reasons: (i) EL2 was already present in the unintentionally doped sample but became important only in the presence of Fe deep acceptors and (ii) Fe stimulated EL2 formation in sample B. Since no deep level transient spectroscopy (DLTS) measurement has been made on the unintentionally doped sample, it is difficult to favor one of the statements against the other. In samples D, E and F, the Fe deep acceptor dominates EL2, and all of the EL2 get compensated by Fe. The maxi-

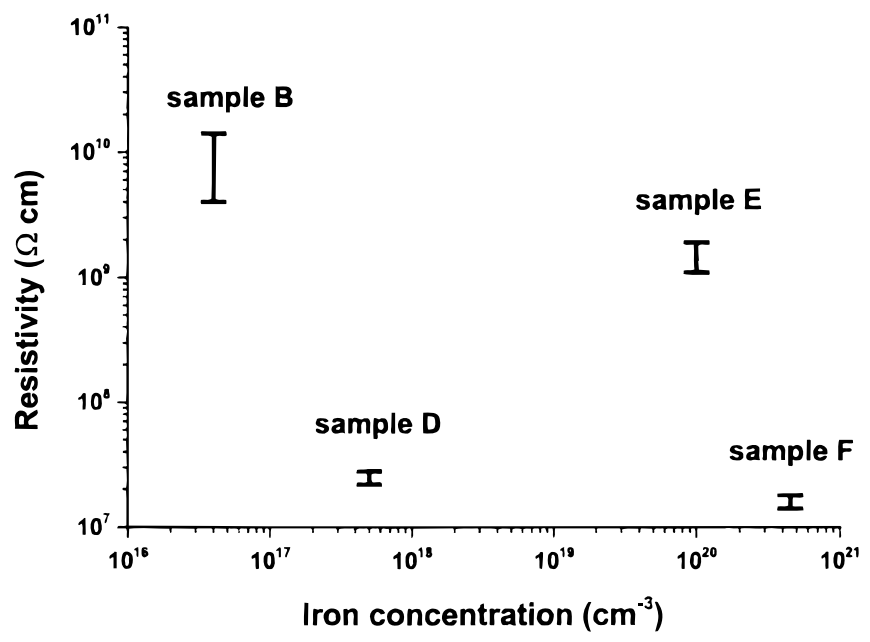

Figure 1. Resistivity at $25^{\circ} \mathrm{C}$ and $0.1 \mathrm{~V}$ of GaAs:Fe as a function of iron concentration. 


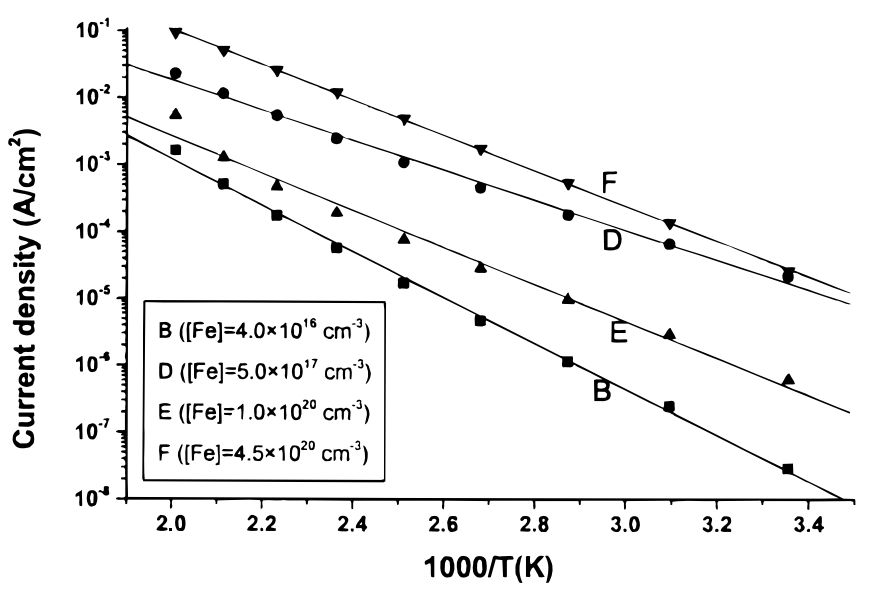

Figure 2. Current density vs. 1/T of GaAs:Fe at $0.1 \mathrm{~V}$.

mum resistivity of sample $\mathrm{E}$ (among $\mathrm{D}, \mathrm{E}$, and $\mathrm{F}$, where Fe dominates as a trap), Fig. 1, suggests that the ratio between uncompensated and compensated iron should be the largest in E.

Time-resolved photoluminescence measurements.-With TR-PL measurements, short lifetimes of carriers in semiconductor materials can be measured. The decay times were $75,38,17$, and 15 ps for samples B, D, E, and F, respectively; it was 95 ps for the unintentionally doped sample. The decay times depend upon the carrier trap concentrations and their capture cross sections. In the case of Fe in $\mathrm{GaAs}, \mathrm{Fe}^{3+}$ acts as an electron trap and $\mathrm{Fe}^{2+}$ acts as a hole trap, whereas EL2 ${ }^{0}$ acts as a hole trap and EL2 ${ }^{+}$as an electron trap. We can estimate the carrier capture cross sections of Fe based on the following two assumptions: (i) The EL2 is dominant in sample B and its concentration in samples $\mathrm{D}, \mathrm{E}$, and $\mathrm{F}$ is same as that in sample $\mathrm{B}$; in samples B, D, and E, all the incorporated Fe are active. Taking into account the Fe and EL2 concentrations, the decay time can then be related to the trap concentrations as follows

$$
\begin{aligned}
& \frac{1}{\tau}-\frac{1}{\tau_{0}}=v_{\mathrm{h}} \sigma_{\mathrm{h}-\mathrm{EL} 2}\left[\mathrm{EL}^{0}\right]+ v_{\mathrm{e}} \sigma_{\mathrm{e}-\mathrm{EL} 2}\left[\mathrm{EL} 2^{0}\right] \\
&+v_{\mathrm{h}} \sigma_{\mathrm{h}-\mathrm{Fe}}\left[\mathrm{Fe}^{2+}\right] \\
&+v_{\mathrm{e}} \sigma_{\mathrm{e}-\mathrm{Fe}}\left[\mathrm{Fe}^{3+}\right]
\end{aligned}
$$

where $\tau$ is the decay time, $\tau_{0}$ the decay time for the unintentionally doped reference sample, $v$ the thermal velocity, $\sigma$ the capture cross sections; $\mathrm{EL} 2^{0}$ and $\mathrm{Fe}^{3+}$ are the uncompensated deep defects and $\mathrm{EL}^{+}$and $\mathrm{Fe}^{2+}$ the corresponding charged species after compensation. The subscripts e and $\mathrm{h}$ stand for electrons and holes, respectively.

We consider first the case EL2 >> Fe (sample B). We assume for this case that all $\mathrm{Fe}$ becomes $\mathrm{Fe}^{2+}$ because the deep donor EL2 com- pensates all $\mathrm{Fe}^{3+}$. This means $[\mathrm{Fe}]_{\mathrm{tot}}=\left[\mathrm{Fe}^{2+}\right]=\left[\mathrm{EL} 2^{+}\right]$. The above equation can then be simplified to

$$
\begin{aligned}
\frac{1}{\tau}-\frac{1}{\tau_{0}}=v_{\mathrm{h}} \sigma_{\mathrm{h}-\mathrm{EL} 2}[\mathrm{EL} 2]_{\mathrm{tot}}+\left(v_{\mathrm{e}} \sigma_{\mathrm{e}-\mathrm{EL} 2}\right. & +v_{\mathrm{h}} \sigma_{\mathrm{h}-\mathrm{Fe}} \\
& \left.-v_{\mathrm{h}} \sigma_{\mathrm{h}-\mathrm{EL} 2}\right)[\mathrm{Fe}]_{\mathrm{tot}}
\end{aligned}
$$

The second case is Fe > EL2 (samples D, E, F), where we assume that all EL2 ${ }^{0}$ becomes EL2 ${ }^{+}$. This means that $\left[\mathrm{Fe}^{2+}\right]=[\mathrm{EL} 2]_{\mathrm{tot}}$ and $[\mathrm{Fe}]_{\mathrm{tot}}=\left[\mathrm{Fe}^{3+}\right]+[\mathrm{EL} 2]_{\mathrm{tot}}$. The general Eq. 2 can then be simplified to

$$
\begin{aligned}
\frac{1}{\tau}-\frac{1}{\tau_{0}}=\left(v_{\mathrm{e}} \sigma_{\mathrm{e}-\mathrm{EL} 2}+v_{\mathrm{h}} \sigma_{\mathrm{h}-\mathrm{Fe}}+v_{\mathrm{e}} \sigma_{\mathrm{e}-\mathrm{Fe}}\right)[\mathrm{EL} 2]_{\mathrm{tot}} & \\
& +v_{\mathrm{e}} \sigma_{\mathrm{e}-\mathrm{Fe}}[\mathrm{Fe}]_{\mathrm{tot}}
\end{aligned}
$$

Equation 4 is used to estimate the electron capture cross section from samples D and E. We assume for this calculation that all incorporated $\mathrm{Fe}$ is active and obtain from the literature ${ }^{4}$ the capture cross sections of EL2 ${ }^{0}$ and EL2 ${ }^{+}$. This yields $\sigma_{\mathrm{e}-\mathrm{Fe}}=7 \times 10^{-18} \mathrm{~cm}^{2}$. Using this value and considering Eq. 3 for sample B and Eq. 4 for sample $\mathrm{D}$, one can extract $\sigma_{\mathrm{h}-\mathrm{Fe}}$ as $2 \times 10^{-15}$ and $[\mathrm{EL} 2]_{\mathrm{tot}}=7 \times 10^{16} \mathrm{~cm}^{-3}$. The values of the electron and hole capture cross sections that are reported in the literature are lower than the ones measured here. Lang and $\operatorname{Logan}^{5}$ report an electron capture cross section of $6 \times$ $10^{-20} \mathrm{~cm}^{2}$ and a hole capture cross section of $2 \times 10^{-16} \mathrm{~cm}^{2}$, both at $300 \mathrm{~K}$. Kleverman et al. ${ }^{6}$ report $1 \times 10^{-19} \mathrm{~cm}^{2}$ for the electron capture cross section at $300 \mathrm{~K}$. The estimated concentration of EL2, $7 \times 10^{16} \mathrm{~cm}^{-3}$, is higher than the iron concentration in sample B and lower than the iron concentration in samples D, E, and F.

\section{Conclusions}

We have grown epitaxial layers of GaAs:Fe with different iron concentrations by HVPE; these layers have been characterized electrically (I-V-T) and optically (TR-PL). Resistivity as a function of Fe has been derived and it is observed that the highest resistivity is obtained by the lowest iron concentration. The capture cross sections of electrons and holes of Fe have also been estimated.

The Royal Institute of Technology assisted in meeting the publication costs of this article.

\section{References}

1. B.-S. Yoo, H. Y. Chu, H.-H. Park, H. G. Lee, and J. Lee, IEEE J. Quantum Electron., 33, 1794 (1997).

2. S. Lourdudoss, B. Hammarlund, and O. Kjebon, J. Electron. Mater, 19, 981 (1990)

3. Properties of Gallium Arsenide, 2nd ed., INSPEC, The Institution of Electrical Engineers, London and New York (1990).

4. D. C. Look and Z.-Q. Fang, J. Appl. Phys., 80, 3590 (1996).

5. D. V. Lang and R. A. Logan, J. Electron. Mater., 4, 1053 (1975).

6. M. Kleverman, P. Omling, L-A. Ledebo, and H. G. Grimmeiss, J. Appl. Phys., 54, 814 (1983). 